\title{
Clinical Management of Contagious Ecthyma in Goats - A Case Report
}

\author{
Manu Jaiswal*, Mohammad Nazeer, Rajat Varshney, Kuldeep Saini, \\ Girjesh Upmanyu and Rupam Sinha
}

Faculty of Veterinary and Animal Science, Institute of Agricultural Sciences, Rajiv Gandhi South Campus, Banaras Hindu University, Barkachha, Mirzapur, (U.P.), India

*Corresponding author

\section{A B S T R A C T}

\section{Keywords \\ Orf, Goat, Pyrexia, \\ Anorexia, \\ Lameness, \\ Pneumonia \\ Article Info \\ Accepted: \\ 10 January 2019 \\ Available Online: \\ 10 February 2019}

Two non descript goats of age 1 and 1.5 years was presented at Veterinary Clinical Complex (VCC), PGIVER, Jaipur with history of pyrexia, anorexia, nasal discharge, lameness and various skin lesions on muzzle, lips and mouth. On physical examination, it was found that the lesion was dry ulcerative and scabby. Auscultation revealed a significant crackling sound suggestive of pneumonia. The aforesaid clinical pictures pointed towards orf infection. Both cases were treated with antibiotics and topical therapy till clinical recovery. Both goats were clinically recovered after treatment.

\section{Introduction}

Orf also known as contagious ecthyma, contagious pustular dermatitis (CPD), sore mouth or scabby mouth (CDC, 2015), is an acute contagious, debilitating and economically important zoonotic viral disease of sheep, goats and some other domesticated and wild ruminants. The affected animal manifests painful skin lesions around the mouth and muzzle on account of which anorexia or starvation usually noticed (Constable et al., 2017). Typical clinical signs in mucous membrane of the oral cavity, tongue, lips and teats are developed sequentially in form of papules, vesicles, pustules, scabs which are important for diagnostic point of view. Contagious ecthyma (Orf) virus belongs to the genus Parapoxvirus of the family Poxviridae (Murphy et al., 2012; Nadeem et al., 2010). Direct / Indirect contact can transmits the virus through broken, scarified or damaged skin.

Orf cases are more often noticed in pasture or manual feeding under drought conditions. Orf virus is hardy as it can resist dry environment and can continue to live for considerable length of time ranging from months to years in dry environments (Radostits et al., 2007). 
Although this disease was reported in all seasons around the world (Nandi et al., 2011), however, outbreaks of the disease in grassland or flattening system are frequently noticed in late summer, autumn and winter. The probability of occurrence of orf infection is more in new born lamb or within a period of 3 to 4 months after birth (Lovatt et al., 2012; Reid et al., 2007). Herd prevalence rates of this disease usually are higher in goats than sheep (Mondal et al., 2006; Scagliarini et al., 2012). Some sheep and goats may act as carrier animals without showing any sign of disease.

\section{History}

Two non pregnant goats of different age group 1 and 1.5 year was presented at VCC, PGIVER, Jaipur with the complain of anorexia, nasal exudates, lameness and various skin lesions on muzzle, lips and mouth.

\section{Clinical observation}

On physical examinations of goats we found dry ulcerative and scabby characteristic lesions around mouth, lips, muzzle and inter digital space were seen (Fig. 1 and 2). Rectal temperature was higher than the normal $\left(103.7^{\circ} \mathrm{F}\right)$ while respiration and pulse rate were in normal range. Also there was presence of nasal exudates with sneezing. On auscultation the lungs, crackling sounds were heard suggestive of pneumonia. Characteristics lesions pointed towards contagious ecthyma.

\section{Treatment and Discussion}

Good personal hygiene measures were taken to avoid further transmission the virus as zoonotic potential of this disease is well known. Symptomatic treatment was instituted for reducing the severity of lesions and prompt recovery. For the treatment of pneumonia and control of secondary bacterial infection, the goats were treated with the Enrofloxacin (Floxidin 10\%) @ $5 \mathrm{mg} / \mathrm{kg}$ body weight intramuscularly S.I.D. for 5 days, intravenous injection of Flunixin Meglumine (Megludyne) @ 2.2mg/kg body weight as a NSAID B.I.D. for 3 days and Catcough (as a cough electuary with immunomodulatory properties) @ $15 \mathrm{gm}$ T.I.D for 5 days. Povidone Iodine (Cipladine-5\%) was applied on scab lesions daily till healing. This intervention had shown drastic improvement in the clinical condition of both the goats.

In this case the goats were presented with signs of severe generalized proliferative, ulcerative and dry scaby lesions in the skin of oral cavity, interdigital space. Orf virus gains entry through abraded skin and replicates in epidermal cells which in turn lead to sequential development of peculiar skin lesions through multiple stages i.e. erythema, macule, papule, vesicle, pustule, scab, and scar (Gelberg et al., 2012; Hargis et al., 2012 and Tizard, 2013). Although infection is confined to squamous epithelium of the oral cavity, eyelids, teats and coronary band of affected animals in combination of secondary bacterial infections (Gelberg et al., 2012; Hargis et al., 2012 and Tizard, 2013), however, lesions extend to the squamous epithelium of the esophagus, rumen and omasum, causing ulcerative gastroenteritis (Zachary et al., 2012). Nandi et al., (2011) also observe the characteristic multifocal, severe proliferative dermatitis in Orf infected goats in combination with chronic pneumonia, arthritis and moderate to severe lymphadenopathy. The clinical pictures of present cases are in concur with (Kumar et al., 2015 and Abdullah et al., 2015) who reported vesiculo-proliferative lesions on the external and internal surfaces of the mouth, lips, face, ears, nostrils, scrotum, udder, vulva and interdigital region characterized the disease in sheep and goats. 
Fig.1 Shows dry, ulcerative and scabby lesions around mouth, lips and muzzle

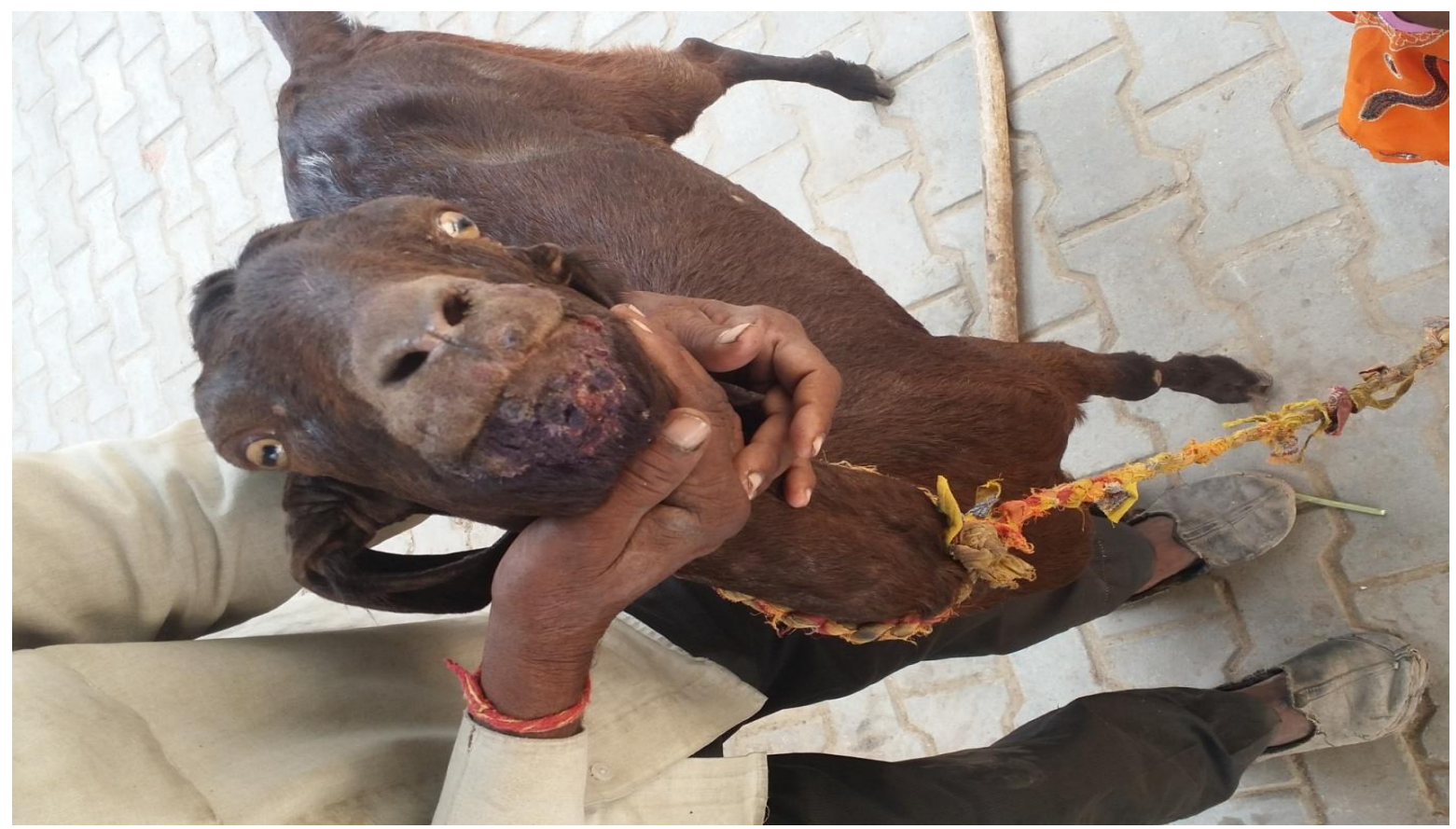

Fig.2 Shows dry, ulcerative and scabby lesions around mouth, lips, muzzle and nasal Exudate

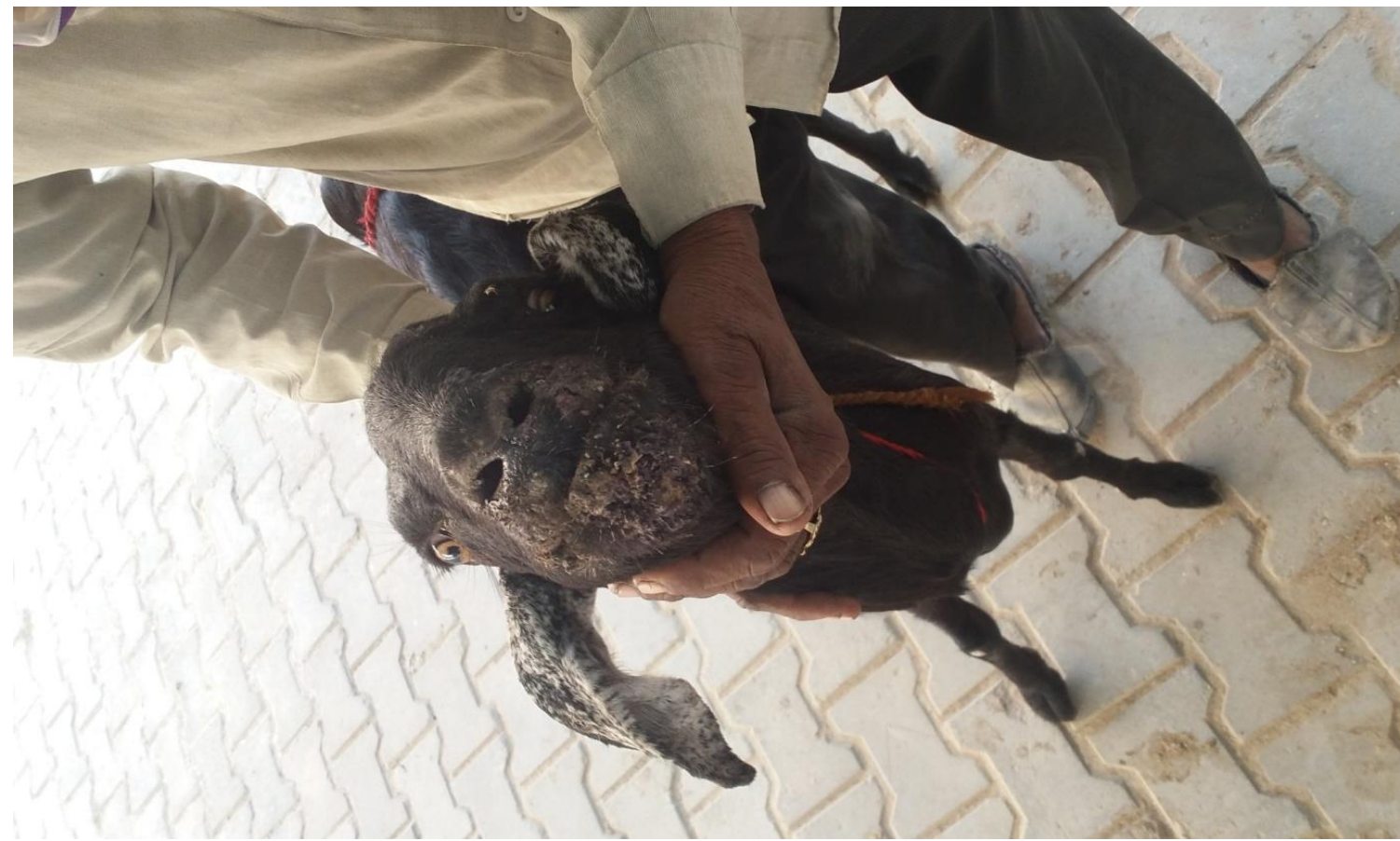

In the present case, the goat showed signs of pneumonia, which could have been precipitated by extension of the lesion into the respiratory tract or secondary bacterial complication. Radostits et al., (2007) have described severe systemic reactions with extension to the alimentary tract and trachea that may result in gastroenteritis and 
bronchopneumonia in cases of Orf. Specific therapy is not recommended for combating this viral infection. However, both goats were treated with application of Povidone Iodine on the scab lesions daily till healing. The aim of treatment was reducing the severity of the lesions and speed recovery as removal of the scab may delay healing, this approach agrees with (Radostits et al., 2007 and Nandi et al., 2011) and the supportive treatment that includes the topical application of ointments or astringent lotions and systemic antimicrobial administration against secondary bacterial complications may speed recovery.

Contagious ecthyma is a zoonotic disease that causes huge economic loses, so early detection and clinical management can resolve the condition early in the flock. Though, the disease is self-limiting and secondary bacterial infection causes the complication, so, antibiotics, antiinflammatory and topical therapy helpful in the recovery.

\section{Acknowledgement}

Authors are thankful to Dean of PGIVER, Jaipur for providing necessary facility for the work.

\section{References}

Abdullah, A. A., Ismail, M. F. Bin., Balakrishnan, K. N., Bala, J. A., Hani, H. Abba. Y., Mohd-Lila, M. A. 2015. Isolation and phylogenetic analysis of caprine Orf virus in Malaysia. Virus Dis. 26(4): 255-259.

CDC. 2015. Orf virus (sore mouth infection). Centres for disease control and prevention (CDC), 1600 Clifton Rd. Atlanta Georgia, GA 30333 USA.

Constable, P. D., Hinchcliff, K. W, Done, S. H. and Grunberg, W. 2017. Veterinary
Medicine. A textbook of the diseases of cattle, sheep, goats and horses 11th Edn, WB Saunders Co. pp. 1593-1596.

Gelberg, H. B., Zachary, J. F. and McGavin, M. D. 2012. Alimentary system and the peritoneum, omentum, mesentery, and peritoneal cavity in Pathologic Basis of Veterinary Disease, Eds., pp. 326-327, Elsevier, St. Louis, Mo, USA, 5th edition.

Hargis, A. M., Ginn, P. E., Zachary, J. F. and McGavin, M. D. 2012. The integument in pathologic basis of veterinary disease, Eds., pp. 1023, Elsevier, St.Louis, Mo, USA, 5th edition.

Kumar, R., Trivedi, R. N., Bhatt, P., Khan, S. H., Khurana, S. K., Tiwari, R., Karthik, K., Malik, Y. S. and Dhama, K. C. R. 2015. Contagious pustular dermatitis (orf disease) - epidemiology, diagnosis, control and public health concerns. $A d v$. Anim. Vet. Sci. 3(12): 649-676.

Lovatt, F., Barker, W., Brown, D. and Spooner, R. 2012. Case-control study of orf in preweaned lambs and an assessment of the financial impact of the disease. The Veterinary record, 170: 673-673.

Mondal, B., Bera, A., Hosamani, M., Tembhurne, P. and Bandyopadhyay, S. 2006. Detection of orf virus from an outbreak in goats and its genetic relation with other para poxviruses. Veterinary research communications, 30: 531- 539.

Murphy, F. A., Fauquet, C. M., Bishop, D. H., Ghabrial, S. A., Jarvis, A., Martelli, G. P., Mayo, M. A. and Summers, M. D. 2012. Virus taxonomy: classification and nomenclature of viruses. Springer Sci. Bus. Media.

Nadeem, M., Curran, P., Cooke, R., Ryan, C. and Connolly, K. 2010. Orf:contagious pustular dermatitis. Ir. Med. J. 103(5): 152-153.

Nandi, S. De. UK. and Choudhary, S. 2011. Status of contagious ecthyma of orf 
disease in goat. Small Rumin Res, 96: 73-82.

Radostits, O. M., Gay, C., Hinchcliff, K. W. and Constable, P. D. 2007. A textbook of the diseases of cattle, horses, sheep, pigs and goats, Saunders Elsevier, Edinburgh London.

Reid, H. W. and Rodger, S. M. 2007. Orf Diseases of Sheep, Aitken. Blackwell Publishing, Ed. 297-302.

Scagliarini, A., Piovesana, S., Turrini, F., Savini, F., Sithole, F. and McCrindle, C.
M. 2012. Orf in South Africa: endemic but neglected: original research. Journal of Veterinary Research, 79: 1-8.

Tizard, R. 2013. Regulation of adaptive immunity in Veterinary Immunology, pp. 217, Elsevier, St. Louis, Mo, USA, 9th edition.

Zachary, J. F. and McGavin, M. D. 2012. Mechanisms of microbial infections in pathologic basis of veterinary disease, Eds., pp. 210, Elsevier, St. Louis, Mo, USA, 5th edition.

\section{How to cite this article:}

Manu Jaiswal, Mohammad Nazeer, Rajat Varshney, Kuldeep Saini, Girjesh Upmanyu and Rupam Sinha. 2019. Clinical Management of Contagious Ecthyma in Goats - A Case Report. Int.J.Curr.Microbiol.App.Sci. 8(02): 879-883. doi: https://doi.org/10.20546/ijcmas.2019.802.099 